\title{
QUEBRA DE DORMÊNCIA EM SEMENTES DE CROTALARIA
}

\author{
DORMANCY BREAK OF CROTALARIA SEEDS
}

\author{
Zaida Inês Antoniolli* \\ Ecila Maria Nunes Giracca*
}

\author{
Rogério Antônio Bella** \\ Paulo Sergio Thomas***
}

\section{RESUMO}

A germinação de sementes de quatro espécies de Crotalaria foram avaliadas após tratamentos químicos, físicos e mecânicos de superação de impermeabilidade do tegumento. Os métodos mais eficientes para a quebra de dormência foram: para a $\mathbf{C}$. retusa, a escarificação em engenho e embebição em água fervente por cinco minutos; para a C. espectabilis a escarificação química em $\mathrm{H}_{2} \mathrm{SO}_{4}$ e embebição prévia em água destilada à temperatura ambiente; para a C. mucronata a escarificação em engenho, os quais possibilitaram a maior percentagem de plântulas normais. Já para a C. grantiana, nenhum tratamento testado foi estatisticamente superior à testemunha.

Palavras-chave: Crotalaria sementes, dormência, germinação.

\section{SUMMARY}

Seed germination of four Crotalaria species were evaluated after physical, chemical and mechanical treatments to overcome impermeability of seed coat. The most efficient methods to break dormancy were: for $\mathbf{C}$. retusa mechanical seed scarfication followed by seed imbibition in boiling water for five minutes; for $\mathbf{C}$. spectabilis seed imbibing in destilated water at room temperature and seed chemical scarification in $\mathrm{H}_{2} \mathrm{SO}_{4}$; and rinsed in tap water for $\mathbf{C}$. mucronata mechanical seed scarification; for C. grantiana none tested treatments improved dormancy break. The dormancy break efficiency was measured based on percentage of normal seedling.

Key words: Crotalaria, seeds, dormancy, germination.

\section{INTRODUÇÃO}

As sementes de espécies do gênero Crotalaria Dill. ex. Linn., com grande utilização na adubação verde, apresentam impermeabilidade no tegumento que causa dormência, o qual é uma barreira à pronta germinação. Para AMEN (1968), as causas de dormência podem ser atribuídas à presença de embriões rudimentares, embriões fisiologicamente imaturos, tegumento mecanicamente resistente, presença de inibidores de germinação e tegumentos impermeáveis à água.

As sementes deste gênero, apresentam o tẹumento impermeável à água, o que resulta em um grande número de sementes duras. A estrutura responsável pela impermeabilidade à água, é o tegumento onde as células da camada palissádica são espessas e recobertas externamente por uma camada cuticular cerosa (POPINIGIS, 1977).

As regras de analise de sementes (BRASIL, 1981) recomendam alguns métodos para a indução à germinação de sementes duras de diversas espécies. Tais métodos, geralmente, não satisfazem principalmente num tratamento visando uma semeadura no campo. Pois estes métodos não envolvem escarificações químicas ou mecânicas que segundo ROCHA (1961) e FlGUEIREDO \& POPINIGIS (1979), seriam os métodos mais eficazes na melhoria da germinação de espécies com sementes duras.

MATWEUS (1947), verificou que o efeito das rotaçōes e do tempo de escarificação de sementes de Aeschynomene americana $L$, Alysicarpus vaginalis $L$, Crotalaria incana L. $\theta$ C. spectabilis Roth., sobre a germinação, dependem da espécie e da dureza do tegumento; Jones apud CARNEIRO et al (1985), também escarificou sementes de $C$. achroleuca num moinho a martelo, com a velocidade de 1750 rotações por minuto e conseguiu $60 \%$ de germinação.

Tratamentos físicos, químicos e mecânicos de superação da impermeabilidade do tegumento, também

\footnotetext{
* Biokógo, Engenheiro Agrônomo, respectivamente, professores do Departamento de Solos, Centro de Ciências Rurais (CCR) da Universidade Federal de Santa Maria (UFSM). 97119-900. Santa Maria, RS.

** Engenheiro Agrônomo, Ph.D. professor do Departamento de Fitotecnia, CCR - UFSM.

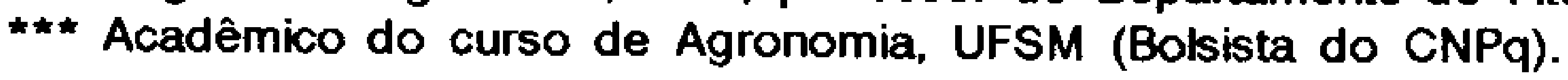


foram utilizados por MÂEDA \& LAGO (1986), na germinação de sementes recém colhidas de mucuna-preta (Styzolobium atterrimum). Eles obtiveram resultados mais efetivos com os tratamentos de remoção da pequena porção do tegumento na região distal da semente, ou seja, na região oposta ao eixo embrionário, e o de imersão em ácido sulfúrico concentrado, por 5, 10, 15 e 20 minutos, que exibiram germinação acima de $88 \%$. Embebição em água à temperatura ambiente, em solventes orgânicos e aplicação de calor ou frio à seco, foram inócuos, não diferindo da testemunha, que apresentou germinação de apenas $23,9 \%$.

Em experimentos com escarificação mecânica na germinação de sementes de soja perene, CARNEIRO et al (1985) concluíram que este método demonstrou ser prático e satisfatório para aumentar a germinação das sementes, que tinham o tegumento impermeável a água por ocasião da semeadura.

Em pesquisas recentes, AlTA et al (1991), WILDNER et al (1991a) e (1991b), visando aprimorar o uso de Crotalaria spp na adubação verde, depararam-se com o problema de emergência no campo, por falta de maiores opções no tratamento de sementes duras, que usasse métodos mais simples. Assim, com o objetivo de obter maiores informações para o aumento da percentagem de germinação, foram estudados diferentes métodos de quebra de dormência em $\mathbf{C}$. mucronata, $\mathbf{C}$. retusa, C. spectabilis e C. grantiana

\section{MATERIAL E MÉTODOS}

O experimento foi realizado no Laboratório de Sementes do Departamento de Fitotecnia da Universidade Federal de Santa Maria-UFSM, em 1990, com sementes de C. spectabilis, C. retusa, $\mathbf{C}$. mucronata e C. grantiana Todas as espécies, foram produzidas na área experimental do Departamento de Solos (UFSM), no mesmo ano

As sementes foram submetidas aos seguintes tratamentos: 1) Escarificação química em ácido sulfúrico $\left(\mathrm{H}_{2} \mathrm{SO}_{4}\right.$ concentrado - PA, por 15 minutos à temperatura de $22^{\circ} \mathrm{C}$, seguida de imediata lavagem em água corrente, por aproximadamente 5 minutos); 2) Imersão em hipoclorito de sódio $(\mathrm{NaClO})$, por 30 minutos a temperatura de $30^{\circ} \mathrm{C}$; 3) Pré-friagem por sete dias a $5^{\circ} \mathrm{C}$; 4) Escarificação em engenho de arroz modelo Kepler Weber, com abertura 13 para $C$. retusa 10 para $C$. spectabilis e 8 para C. grantiana e C. mucronata 5) Imersão em água destilada fervente por cinco minutos; 6) Embebição em água destilada à temperatura ambiente por 24 horas; 7) Escarificação das sementes com areia em um frasco, agitando-o durante três minutos. $O$ efeito dos tratamentos foi comparado com uma testemunha, cujas sementes não receberam nenhum tratamento.
Na escarificaçăo mecânica, pelo engenho de provas, após a passagem das sementes de cada espécie, este foi aberto e esterilizado com álcool $70 \%$. Já na escarificaçāo em areia, foi sempre usada novas porções de areia estéril.

Após os tratamentos, quatro repetições de 100 sementes foram colocadas a germinar sobre papel germitest e em caixas gerbox, dentro do germinador, regulado para a temperatura de 20 a $30^{\circ} \mathrm{C},\left(20^{\circ} \mathrm{C}\right.$ por 16 horas e $30^{\circ} \mathrm{C}$ por 8 horas), sendo que a primeira contagem foi aos sete dias, e a última aos 14 dias (BRASIL, 1981). Os dados apresentados são as percentagens de germinação correspondendo à percentagem de plântulas normais, sementes duras e sementes mortas.

A comparação dos tratamentos, foi feita pelo teste de Tukey, ao nível de $5 \%$ de probabilidade (PIMENTEL GOMES, 1970).

\section{RESULTADOS E DISCUSSÃO}

Analisando-se os dados da Tabela 1, observase que, para Crotalaria spectabilis, a maioria dos tratamentos contribuíram para o aumento da percentagem de germinação, com exceção dos tratamentos escarificação em engenho e embebição prévia em água fervente. Nestes dois casos, para esta espécie, a redução na germinaçāo em relação a testemunha, pode ser devido aos danos mecânicos excessivos ao tegumento, que favoreceu uma grande infestação pelos fungos Aspergillus flavus e Rhizopus sp., que contaminaram as sementes, impedindo o processo germinativo. A melhor superação de dormência, ocorreu com o tratamento embebição prévia em água a temperatura ambiente, que não diferiu estatísticamente do tratamento com $\mathrm{H}_{2} \mathrm{SO}_{4}$. Os tratamentos, $\mathrm{NaClO}$, pré-friagem e areia não forain eficazes, pois apresentaram um grande número de sementes duras no final do teste.

Verifica-se também, que esta espécie foi pouco dormente, pois a testemunha apresentou $64 \%$ de germinação, diferenciando-se estatísticamente do melhor tratamento. Esta melhoria significativa de $26 \%$ de germinação, foi pelo fato das sementes serem préviamente embebidas em água, formulando-se a hipótese do hilo ser a melhor via de penetraçăo da água na semente, pois não se observou sementes duras. A melhoria da germinação observada, envolve também o processo de revigoramento das sementes pela embebição prévia, como propôs HEYDECKER et al (1975).

Para a espécie C. retusa o melhor tratamento observado foi a embebição prévia em água fervente (Tabela 1). Este não diferiu significativamente da escarificação pelo engenho embora, tenha tambem resultado em contaminação pelos fungos A. flavus $\theta$ Fusarium sp., 
Tabela 1 - Percentagem de germinação (PG), sementes duras (SD) e sementes mortas (SM), aos 14 dias de avaliação da Crotalaria spp após tratamentos para a superação da dormência com quatro repetições.

\section{E S P É C I E}

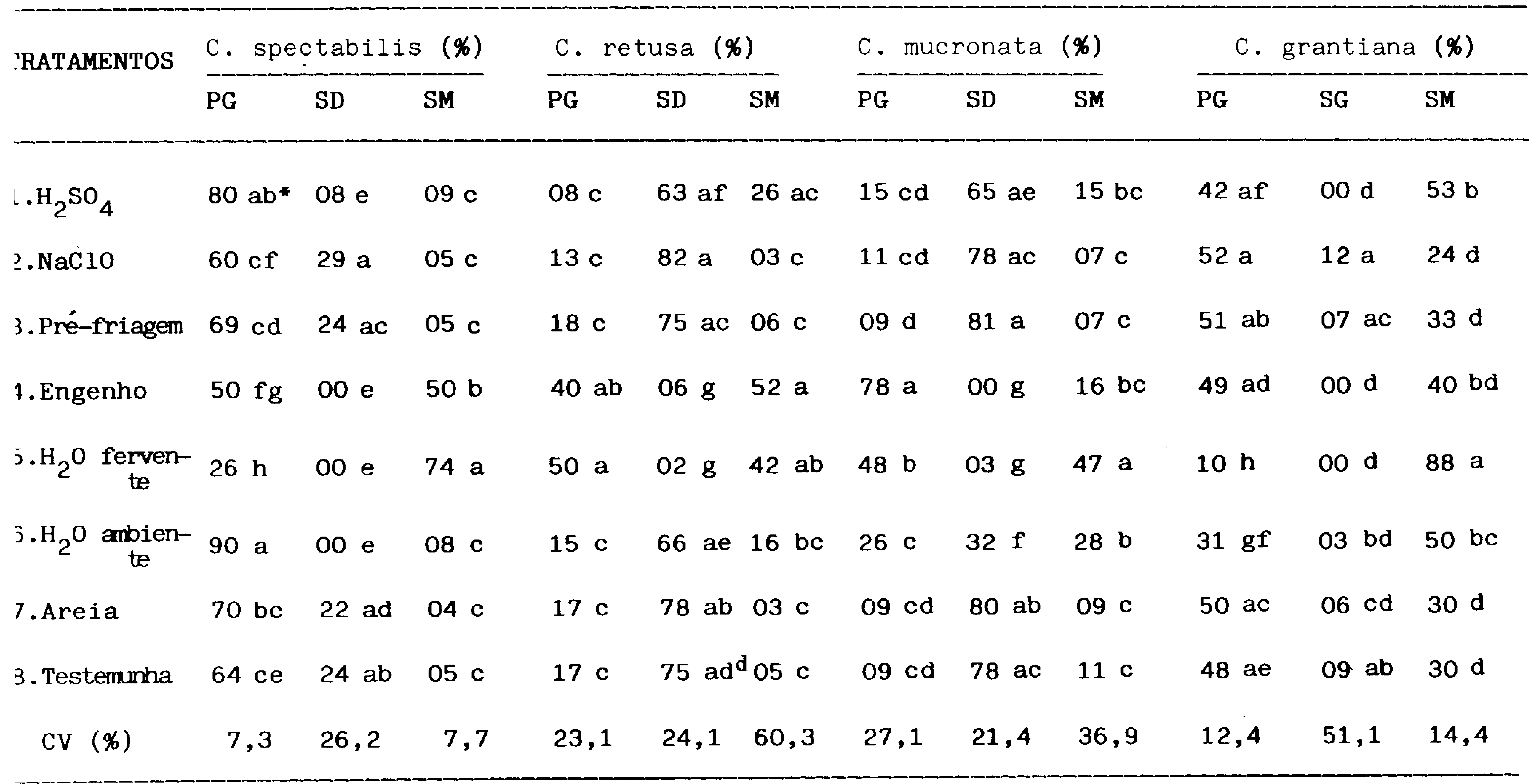

* Médias seguidas de letras iguais, não diferem siginificativamente entre si, segundo teste de Tukey, ao nível de $5 \%$ de probabilidade.

mas em menor intensidade. Os demais tratamentos tiveram uma percentagem de germinação reduzida, com resultado da ineficácia dos tratamentos, pois se verificou grande número de sementes duras no final dos testes.

O tratamento embebição prévia em água a temperatura ambiente, para $C$. retusa foi menos eficiente do que para $\mathbf{C}$. spectabilis Levanta a hipótese de que - mecanismo de penetração da água para esta espécie não seria o hilo, e sim, o tegumento, demonstrado pelas maiores abrasões nas sementes nos tratamentos de escarificação em engenho e embebição prévia em água fervente favorecendo, assim, a penetração da água e, como conseqüência, a maior percentagem de germinação.

Para C. mucronata observa-se que, a maior percentagem de germinação $(78 \%)$ (Tabela 1), foi obtida pela passagem das sementes pelo engenho de provas. Resultado este, que concorda com os obtidos por CARNEIRO et al (1985), muito embora tenha trabalhado com soja perene. $O$ segundo melhor resultado e significativamente inferior ao acima descrito, foi o tratamento com água fervente (48\%), verificando-se também, que os tratamentos acima favoreceram o aparecimento de fungos nas sementes (Fusarium sp. e Aspergillus flavus). Os demais resultaram em baixa percentagem de germinação, não sendo superiores estatísticamente à testemunha. A ineficiência destes tratamentos foi comprovada pela alta percentagem de sementes duras no final do teste, de 65 a $81 \%$.

Para C. grantiana não houve quebra de dormência pois, nenhum tratamento superou a testemunha (Tabela 1). Na análise dos resultados da testemunha observou-se que se trata de um lote de vaixa qualidade inicial, onde apareceram $30 \%$ de sementes mortas no final do teste. Com exceção dos tratamentos $\mathrm{NaClO}$. prefriagem e escarificação em areia, os demais aumentaram significativamente o número de sementes mortas. de. monstrando que os mesmos foram prejudiciais às se. mentes. Apesar deste resultado, não houve interferèncıa de ocorrência de fungos, como se observou nas outras espécies estudadas.

Nas condições do presente trabalho, para as 
diferentes espécies estudadas, verifica-se que:

- a escarificação química $\left(\mathrm{H}_{2} \mathrm{SO}_{4}\right)$ e a embebição prévia em água destilada à temperatura ambiente, proporcio:a:am a melhor quebra de dormência para C. spectabilis;

Júa C. retusa a imersão em água fervente (5 minutos) e escarificaçāo mecânica pelo engenho, foram os mais eficientes tratamentos na melhoria da percentagem de germinaçāo;

- a escarificação mecânica pelo engenho, foi o tratamento que resultou na melhor quebra de dormência para C. mucronata

- nenhum dos tratamentos estudados foram favoráveis para o aumento da percentagem de germinação para C. grantiana

Novas perspectivas de pesquisa, podem ser seguidas pelo aprimoramento da técnica de escarificação mecânica, associada ao tratamento de sementes com fungicidas e revigoramento de sementes, pois as espécies apresentam tamanhos distintos de sementes.

\section{REFERÊNCIAS BIBLIOGRÁFICAS}

AITA, C., CERETTA, C.A., CAMPOS, B.C, et al. Efeito de três espécies de verão no rendimento do milho em sucessão nos sistemas de cultivo mínimo e convencional. IN: REUNIÃO CENTRO-SUL DE ADUBAÇÃO VERDE E ROTAÇÃO DE CULTURAS, 1991. Cascavel, PR. ATA ... Cascavel, PR, Organização das Cooperativas do Estado do Paraná. OCEPAR, 1991, 218 p. p. 133.

AMEN, R.D. A model of seed dormancy. The Bot Rev, New York, v. 34, n. 1, p. 1-31, Jan-Mar, 1968.

BRASIL, Ministério da Agricultura. Regra para Análise de Sementes Brasília: DNPV/DISEM, 1981, 188 p.

CARNEIRO, J.W.P., SILVA, R.F., GARCIA, R., et al. Influência da escarificaçāo mecânica na germinação da soja perene. Revista Brasileira de Sementes Brasília, v. 7, n. 3, p. 161-171, 1985.

FIGUEIREDO, F.J.C., POPININIGIS, S. Superação da dormência de sementes de malva (Urena lobata L.). Belém: EMBRAPA/CPATU, 1979, 18 p. (Comunicado Técnico, 21).

HEYDECKER, W., HIGGINS, J., TURNER, Y.J. Invigoration of seeds. Seed Science \& Technology, Wageningen, v. 3, n. 314, p. 881-888, 1975.

MAEDA, J.A., LAGO, A.A. Germinação de mucuna-preta após tratamentos para superação da impermeabilidade do tegumento. Revista Brasileira de Sementes Brasília, v. 8, n. 1, p.79-84, 1986.

MATWEUS, A.C. The scarification of various legumes seeds with a disc scarifier. J Am Soc Agron, Madison, v. 39, p. 343-345, 1947.

PIMENTEL GOMES, F.Curso de Estatística Experimental 4 ed., Piracicaba: ESALQ, 1970. 468 p.

POPINIGIS, F. Fisiologia da Semente. Ministério da Agricultura. AGIPLAN, Brasília: Vera Cruz, 1977, 289 p.

ROCHA, F.F. Influência da água oxigenada na germinação de sementes de cebola. Olericultura Viçosa, $n$. 1, p. $1-9,1961$

WILDNER, L.P., DADALTO, G.G. Avaliaçāo de sementes de verão para adubação verde, cobertura e recuperação do solo na região oeste Catarinense. I Espécies anuais. IN: REUNIÄO CENTRO-SUL DE ADUBAÇÃO VERDE E ROTAÇÃO DE CULTURAS, 1991a, Cascavel, PR. Ata ... Cascavel, PR, Organizaçāo das Cooperativas do Estado do Paraná. OCEPAR, 1991, 218 p. p. 148.

WILDNER, L.P., DADALTO, G.G. Avaliação de sementes de verão para adubação verde, cobertura e recuperação do solo na região oeste Catarinense. II Espécies semi-perenes e perenes. IN: REUNIÄO CENTRO-SUL DE ADUBAÇÃO VERDE E ROTAÇĀO DE CULTURAS, 1991b, Cascavel, PR. Ata ...Cascavel, PR, Organização das Cooperativas do Estado do Paraná. OCEPAR, 1991, 218 p. p. 149. 